\title{
ASSESSING BEHAVIOURAL INTENTION OF SMALL AND MEDIUM ENTERPRISES IN IMPLEMENTING AN HIV/AIDS POLICY AND PROGRAMME
}

\author{
A PARSADH \\ GAJ VAN DYK \\ Department of Industrial Psychology \\ Faculty of Military Science \\ University of Stellenbosch
}

\begin{abstract}
Small and Medium Enterprises (SMEs) are likely to feel the impact of an HIV/AIDS epidemic through reduced productivity and an increased percentage of absenteeism; staff turnover; recruitment and training costs; cost of employee benefits; and poor staff morale. One of the interventions is to implement an HIV/AIDS policy and programme, yet a literature search showed that psychological studies of SMEs in implementing an HIV/AIDS policy and programme are limited. The present study utilised the model of the theory of planned behaviour (Ajzen, 1988, 1991), which is an extension of the theory of reasoned action (Fishbein \& Ajzen, 1975; Ajzen \& Fishbein, 1980). The intention to implement an HIV/AIDS policy and programme was predicted by the theory of planned behaviour constructs such as attitude, subjective norm and perceived behavioural control. The theory of planned behaviour was found to have limited use in assessing behavioural intention of SMEs in implementing an HIV/AIDS policy and programme.
\end{abstract}

\section{OPSOMMING}

Die uitwerking van die MIV/VIGS pandemie op Klein en Medium Sake-ondernemings sal tot gevolg hê 'n afname in produktiwiteit; 'n toename in personeelafwesigheid, personeelomset, personeelwerwing en -opleidingskoste personeelvoordele; en swak personeel moraal tot gevolg hê. Een manier om die probleem aan te spreek is om 'n MIV/VIGS beleid en program te implimenteer. Navorsing toon dat psigologiese studies van klein en medium sakeondernemings om 'n HIV/VIGS beleid en program te implimenteer, beperk is. Hierdie navorsing steun op die teorie van planmatige gedrag (Ajzen, 1988; 1991), wat 'n verlenging is van die teorie van beredeneerde optrede (Fishbein \& Ajzen, 1975; Ajzen \& Fishbein, 1980). Die oogmerk met die implimentering van 'n MIV/VIGS beleid en program is bepaal deur die teorie van planmagtige gedrag soos waargeneem in houding, subjektiewe norme en waargenome gedragskontrole. Die resultate toon dat die teorie van planmagtige gedrag nuttig is om die gesindhede van werknemers in klein en medium sake-ondernemings te bepaal met die implimentering van 'n MIV/VIGS beleid en program.

HIV/AIDS has emerged as problem that affects most organisations. The World Health Organisation (WHO) indicates that by the end of 1999, 24,5 million adults and children were living with HIV/AIDS in sub-Saharan Africa. The United Nations AIDS report in 2003 estimates that 29,4 million people are now infected. Antenatal HIV prevalence in South Africa increased rapidly from 0,7\% in 1990 to $10,5 \%$ in 1995 and then $22,5 \%$ in 1998 .

Although, it seems that HIV prevalence rates are stabilising at high rates, ranging from $11,2 \%$ to $27,9 \%$, HIV was still exhibiting an upward trend in various provinces in South Africa in 2001. (UNAIDS Epidemiogical Fact Sheet, 2002). It must however, be noted, that there is a great deal of contention regarding statistics on HIV/AIDS prevalence. Projections show that without treatment and interventions to curb the spread of HIV/AIDS, the number of AIDS deaths could be expected to more than double the number of deaths due to all other causes, within the next ten years. The impact could relate to loss of skilled employees due to HIV/AIDS, increased costs on employee benefits, higher company costs due to increased absenteeism and overall reduction on organisational performance.

Christianson (2001), says that HIV/AIDS has been recognised as a major challenge by large companies in South Africa and this is evident from the large number of companies who have formal HIV/AIDS policies, and who have launched joint initiatives and cost-benefit analyses both internally and externally. However, while the costs to business are reco gnised, these are misunderstood in many cases and the small and medium enterprises (SMEs) are often neglected by bigger corporates. The SME sector is segmented into three sets of enterprises (South Africa, 1995). The first set comprises

Requests for copies should be addressed to: A Parsadh, Department of Industrial Psychology, Faculty of Military Science, University of Stellenbosch, Private Bag X2, Saldanha, 7395 survivalist enterprises that operate in the informal economy. The second set comprises micro enterprises that involve the owner, some family members and a few employees. The third set comprises small and medium enterprises that constitute the basis of the formal SME economy. SME enterprises are usually owner-managed, operate from fixed premises and bear all the trappings associated with formality. SMEs play an increasingly important role in the South African economy. Given this significance, SMEs potentially provide a rich source of material for researchers on a range of current themes, one of these being the implementation of HIV/AIDS policies and programmes (Cassell, Nadin, Gray \& Clegg, 2002). As SMEs are often part of a supply chain and provide products and services to society and to large companies, HIV/AIDS will have an impact on the economic sector of South Africa. While large companies may have the resources to manage the impact of HIV/AIDS on their workforces, the SMEs generally lack such resources, making them especially vulnerable (Christianson, 2001; Whiteside \& Sunter, 2000).

Hendry, Arthur and Jones (1995) point out that much theory and research tends to focus on large organisations. Two inferences arising from this may discourage research on SMEs. The first inference is that SMEs are less important than large organisations, and the second is that SMEs should learn from these larger organisations. The assumptions may appear to be true within the South African SME sector. However, there seems a lack of cognitive empirical findings about SMEs in dealing with HIV/AIDS in the workplace. A plausible explanation for this is that the SME workplace is not associated with high-risk behaviours that lead to the transmission of HIV (Goss \& Adam-Smith, 1995). Thus, little attention has been given in explaining the behavioural intention of SMEs in implementing an HIV/AIDS policy and programme in the workplace (Coates \& Feldman, 1997; Keil \& 
Schellenberg, 1998; Wager, Remien \& Carballo-Dieguez, 1998). This current practice could have a disastrous effect on workers in the SME sector.

Stanton, Kim, Galbraith and Parrot (1996) and Kirby (1995) claim that a prerequisite for understanding any intervention is a sound theoretical behaviour model. South African SMEs thus need to ensure that their interventions are based on research in order to foster effective human resource (HR) related policies and strategies for dealing effectively with HIV/AIDS in the workplace. The Theory of Planned Behaviour is one such useful model. The model explicitly focuses on the construct of intention and offers a plausible explanation for behavioural intention from a social cognitive psychological perspective (Ajzen, 1991, 1998).

In recent years, the main approach to explain the relationship of attitudes and behaviour was an integration of models of behaviour, including additional determinants, such as social norms or intentions (Olson \& Zanna, 1993). The most widely researched of these models is arguably the Theory of Reasoned Action (Ajzen \& Fishbein, 1980; Fishbein \& Ajzen, 1975) and Planned Behaviour (Ajzen, 1998, 1991; Ajzen \& Madden, 1986). The Theory of Reasoned Action posits intention as the proximal determinant of behaviour. Intention is defined as the motivation required in performing a particular behaviour. Therefore the more one intends to perform a behaviour, the more likely is its performance (Ajzen \& Fishbein, 1980; Fishbein \& Ajzen, 1975). Within this framework, intention is determined by attitudes (general positive and negative evaluations of behaviour) and subjective norm (global perceptions of social pressure). Planned Behaviour (TPB) is an extension of the Theory of Reasoned Action (TRA) that includes measures of control belief and perceived behavioural control (PBC). The inclusion of $\mathrm{PBC}$ as a predictor of behaviour is based on the rationale that by holding the intention constant, PBC increases the likelihood that the behaviour will be successful.

TPB is well supported by research (Manstead \& Parker, 1995; Jonas \& Doll, 1996). Godin and Kok (1996) showed that TPB accounted for $41 \%$ of the variance in behavioural intentions $(\mathrm{R}=0,64,76$ correlations $)$ and $34 \%$ of the variance in behaviours ( $\mathrm{R}=0,58,35$ correlations) for a range of health behaviours. In terms of behavioural prediction, the TPB provides an improvement on the Health Belief Model (HPB), Social Cognitive Theory and Protection Motivation Theory (Conner \& Norman, 1994; Quine, Rutter \& Arnold, 1998). Hardeman, Johnston, Johnstan, Bonetti, Wareham and Kinmonth (2002) found that TPB does have utility as a social cognition model to predict intentions and behaviour. Armitage and Conner (1999a) assessed the predictive validity of the theory of planned behaviour in the context of food choice and found that the model was a robust predictor of food choice.

Quine, Rutter and Arnold (1998), used the HPB and TPB model to predict and understand the use of protective helmets among schoolboy cyclists. The variance explained for the HBM was $18 \%$ compared with $43 \%$ for the TPB and the TPB model showed that the leading predictor of intention was a subjective norm. It was found that TPB was a more reliable model indicating greater economy and less redundancy than the HBM, which substantiates the choice to use the TPB in the present study.

The purpose of the study was to utilise the Theory of Planned Behaviour prediction model to understand factors influencing the decision to implement an HIV/AIDS policy and programme among a sample of SMEs. The factors applied will assess the effect of attitude, subjective norm and or social norm and perceived behavioural control of SMEs in implementing an HIV/AIDS policy and programme.

\section{METHOD}

The explanatory nature of the research using variables of attitude, social norm and perceived behavioural control in explaining behavioural intention to implement an HIV/AIDS policy and programme, justifies an ex post facto correlational design (Kerlinger \& Lee, 2000). A cross sectional survey sample design was used, in which a sample was drawn from the population at one time (Shaughnessy \& Zechmeister, 1997). This design can also be used to evaluate interrelationships among variables within the population.

\section{Sample}

A random sampling procedure for selection proved impossible, as the population is so large and trying to find a sampling frame proved difficult. A non-probability sample was therefore selected on the basis of availability (i.e those SMEs that were available at that point in time). The researcher also experienced difficulties when trying to get owner-managers to complete questionnaires, whilst conducting their businesses. Finally, however, forty three owner-managers of SMEs voluntarily completed the questionnaires in the Boland area of the Western Cape, of which generalisation to the population may be reduced.

\section{Measuring Instrument}

The instrument comprising several parts was developed by researcher. The first section explained the purpose of the study, while the second contained instructions for completing the questionnaire, together with assurances of anonymity and confidentiality. The third section assessed the various constructs contained in the Theory of Planned Behaviour, namely, the intention to implement an HIV/AIDS policy and programme, attitudes towards the behaviour, subjective norms, and perceived behavioural control (PBC). Finally the fourth section solicited demographic information.

\section{Procedure}

Small and medium enterprises were selected within the Boland business district. The only criterion for inclusion in the study was that participants were either owners or managers of SMEs. The sample is however, given the large number and diverse sectors of SMEs not totally representative of all SMEs. The sample was therefore drawn from the Boland area due to availability (Kerlinger \& Lee, 2000).

After the literature review free response, semi-structured interviews among twelve business owner-managers in the Boland Area were conducted to elicit salient outcome beliefs and facilitating or inhibiting factors that were associated with implementing an HIV/AIDS policy and programme. Individuals were asked for their perceptions of the existence of resources or barriers that may help or hinder the performance of implementing an HIV/AIDS policy and programme (Ajzen, 1991). Content analysis was performed and the generated variable items were included in the third section of the questionnaire. The purpose of the questionnaire was to establish the attitudes, subjective norms and $\mathrm{PBC}$ towards implementing a HIV/AIDS policy and programme. The questionnaire was individually administered by the researcher to the owner-managers of the selected SMEs in the Boland business district during July and August 2003 and the respondents were given a choice about participation in the study. The researcher explained that the research was voluntary and that responses would be kept anonymous and confidential. To further ensure anonymity, names of participants and company names were not included in the questionnaire. The purpose and instructions were however included in the questionnaire. 
Variables

The following variables were used:

a. Intention. The participants' intention to implement an HIV/AIDS policy/programme was assessed using three items, each on a 7-point bipolar $(-3$ to +3$)$ scale as suggested by Ajzen and Fishbein (1980); Ajzen (1991) and Armitage and Conner (1999b). The items were:

i. "I intend to implement an HIV/AIDS policy/programme in the future"

ii. "I plan to implement an HIV/AIDS policy/programme in the workplace"

iii. "I want to implement an HIV/AIDS policy/programme in the workplace".

All items were assessed using extremely unlikely-extremely likely as opposite scale points. The mean of these items produced a composite scale which was included in the statistics.

b. Attitude. An indirect measure of attitude was assessed and derived from the multiplicative combination of the perceived likelihood of salient outcomes, and the evaluation of those outcomes. The generated items after perceptions of twelve owner-managers were elicted, yielded five outcome beliefs. Although Armitage \& Conner (1991), used five items, future research in this domain should consider more items to yield stronger reliability. Notwithstanding, the five outcome beliefs were:

i. "Implementing an HIV/AIDS policy/programme helps me to eliminate discrimination in the workplace".

ii. "By implementing an HIV/AIDS policy and programme, I can create a non-discriminatory workplace".

iii. "In implementing an HIV/AIDS policy/programme, I can promote openness/disclosure about HIV status".

iv. "Implementing an HIV/AIDS policy/programme helps me to break down fear of stigma and rejection".

v. "Implementing an HIV/AIDS policy/programme, will help me assess and reduce the impact of HIV/AIDS in the workplace".

Likelihood was measured on a 7-point $(+1$ to +7$)$ unipolar scale and evaluation was measured on a 7 point $(-3$ to +3$)$ bipolar scale (Ajzen \& Fishbein , 1980, Ajzen, 1991, Armitage \& Conner, 1991). Cronbach'sá were $0,84(\mathrm{p}<0,05)$ as shown in Table 6.

c. Subjective Norm. A global measure of subjective norm was measured with a composite score, derived from four items. These items were:

i. "People who are important to me think (I should implement/should not implement) an HIV/AIDS policy/ programme".

ii. "People who are important to me would (approve/ disapprove) of me implementing an HIV/AIDS policy/ programme".

iii. "People who are important to me want me to implement an HIV/AIDS policy/programme (strongly agree/strongly disagree)"

iv. "I feel under social pressure to implement an HIV/AIDS policy/programme (strongly agree/strongly disagree)" (Ajzen \& Fishbein, 1980; Ajzen, 1991). Cronbach's á were $0,62(\mathrm{p}<0,05)$.

d. Control beliefs (PBC). Indirect measures of six control beliefs were measured on a 7 point Likert scale by assessing respondents' perception of the frequency of occurrence of factors that would facilitate or inhibit the implementation of an HIV/AIDS policy/programme in the workplace. Items were anchored by "never/frequently" were multiplied by the perceived power of the factors to facilitate or inhibit the behaviour (anchored by "less likely/most likely") (Ajzen, 1991). These beliefs reflected both internal and external control factors. These items were: i. "I do not have time to implement an HIV/AIDS policy/programme".

ii. "Implementing an HIV/AIDS policy/programme costs too much money".

iii. "I do think about implementing an HIV/AIDS policy/programme".

iv. "To implement an HIV/AIDS policy/programme is inconvenient".

v. "I do not know where to get help to implement an HIV/AIDS policy/programme".

vi. "I lack the ability to implement an HIV/AIDS policy/programme" (Ajzen \& Fishbein, 1980; Ajzen, 1991; Armitage \& Conner, 1999a). Cronbach's á was 0,73 $(\mathrm{p}<0,05)$.

e. Behaviour. Two behaviour measures were included in order to assess the extent to which implementing an HIV/AIDS policy/programme may be prone to reporting biases. The first was a self-perception behaviour measure: "I implemented an HIV/AIDS policy/programme in the last six months". Items were measured on a 7 point scale (anchored by strongly disagree/strongly agree). The responses on strongly disagree/strongly agreed was reduced to yield a response either (No/Yes) respectively and retained in the analysis. The second item was a question "I am currently implementing a HIV/AIDS policy/programme, (Yes/No)".

\section{RESULTS AND DISCUSSION}

\section{Descriptive Statistics}

A final sample of $\mathrm{N}=43$ was used for the analyses. Table 1 shows a mean age of owner-mangers who participated in the study was 33,98 ( $\mathrm{SD}=9,99$ years). The number of employees in the various SMEs, ranged from 2 to 40 , with a mean of $11,4(S D=10,11)$. The company mean age was $(\mathrm{M}=8,67)$ years and ranged from 0,5 to 36 years with $(\mathrm{SD}=9,59)$. The mean for the number of employees $(\mathrm{M}=11,4)$; company age $(\mathrm{M}=8,67)$ and ownermanager $(\mathrm{M}=33,98)$ are shown in Table 1 . Of the respondents, $60,5 \%$ were male, and $39,5 \%$ were female as shown below in Table 1.

TABLE 1

SAMPLE Distribution

\begin{tabular}{lcccccc}
\hline & N & Range & $\begin{array}{l}\text { Mini- } \\
\text { mum }\end{array}$ & $\begin{array}{l}\text { Maxi } \\
\text { mum }\end{array}$ & Mean & Std. Dev \\
\hline Number of employees & 43 & 38,00 & 2,00 & 40,00 & 11,40 & 10,11 \\
Company age & 43 & 35,50 & 0,50 & 36,00 & 8,67 & 9,59 \\
Owner-manager & 43 & 39,00 & 21,00 & 60,00 & 33,98 & 9,99 \\
Valid N (listwise) & 43 & & & & & \\
Male $(26=60,5 \%)$ & & & & & & \\
Female $(17=39,5 \%)$ & & & & & & \\
\hline
\end{tabular}

TABLE 2

IMPLEMENTATION OF HIV/AIDS POLICY AND PROGRAMME IN THE LAST SIX MONTHS

\begin{tabular}{lcccc}
\hline "Strongly disagreed"(1) & $\begin{array}{c}\text { "Strongly } \\
\text { agreed" (7) }\end{array}$ & Male & Female & Total \\
\hline "I implemented a HIV/AIDS & 1 & & & 35 \\
policy/programme in the & 2 & $21(49 \%)$ & $14(33 \%)$ & 3 \\
last six months" & 3 & 1 & 2 & 1 \\
& 5 & 1 & & 2 \\
& 6 & 1 & 1 & 1 \\
Total & 7 & 1 & & 1 \\
\hline
\end{tabular}


The comparison between implementation in the last six months and gender, indicate that 21 males and 14 females strongly disagreed with the item "I implemented an HIV/AIDS policy and programme in the last six months" anchored with a scale "Strongly Disagree (1)/ Strongly Agree (7). Overall 49\% of males indicated that they strongly disagreed with implementing an HIV/AIDS policy/programme in the last six months, whereas $33 \%$ of females indicated that they strongly disagreed with implementing a policy/programme in the last six months (Table 2). Further analysis in reducing the above scales to either (No/Yes) respectively, yields that $49 \%$ of males and $33 \%$ females did not implement a HIV/AIDS policy/programme in the last six months respectively.

The comparison between implementation of an HIV/AIDS policy and programme in the last six months and the number of employees show that the company size of three and eight employees rated 5 on a 7 point scale (strongly disagree/strongly agree), whereas company size, with 25 employees rated 6 . Only one company rated 7 i.e. strongly agreed with implementing an HIV/AIDS policy and programme in the last six months. Overall, 35 companies (i.e. $81 \%)$ rated "strongly disagree" to implementing an HIV/Aids policy and programme (Table 2).

\section{TABLE 3}

CURRENTLY IMPLEMENTING A HIV/AIDS POLICY AND PROGRAMME

\begin{tabular}{lcccc}
\hline "Yes/No" & & Male & Female & Total \\
\hline $\begin{array}{l}\text { "I am currently } \\
\text { implementing a }\end{array}$ & Yes & 2 & 1 & 3 \\
$\begin{array}{l}\text { HIV/AIDS policy/ } \\
\text { programme" }\end{array}$ & No & 24 & 16 & 40
\end{tabular}

$\mathrm{N}=43$

On a categorical scale Yes/No "I am currently implementing an HIV/AIDS policy/programme", overall, $93 \%$ of the respondents (owner-managers) of SMEs indicated that they are not currently implementing an HIV/AIDS policy/programme, whilst only $7 \%$ of the owner-managers were currently implementing an HIV/AIDS policy and programme (Table 3). Past behaviour (implementing an HIV/AIDS in the last six months), yielded that $82 \%$ did not implement a HIV/AIDS policy/programme, whereas $93 \%$ of respondents (ownermanagers) are not currently implementing a HIV/AIDS policy/programme.

\section{TABle 4}

\section{MODEL SUMmaRY}

\begin{tabular}{lccccccc}
\hline Model & $\mathbf{R}$ & $\mathrm{R}^{2}$ & Adjusted R $^{2}$ & $\mathrm{~F}$ & $\mathrm{df1}$ & $\mathrm{df2}$ & $\mathrm{p}(\mathrm{F})$ \\
\hline TPB & 0,550 & 0,302 & 0,248 & 5,629 & 3 & 39 & $0,003^{*}$ \\
\hline
\end{tabular}

Predictors: (constant) PBC, Attitude, Subjective Norm

* $\mathrm{p}<0,01$

To test the TPB model, a multiple regression analysis was performed using intention as the dependent variable and attitude, subjective norm and $\mathrm{PBC}$ as the independent variables. The analysis in Table 4 indicates that the regression model was reasonably significant $(\mathrm{F}(3,39)=5,629 ; \mathrm{p}<0,01)$ yielding a multiple correlation coefficient of $\mathrm{R}=0,550$ containing the independent variables attitude, subjective norm and perceived behavioural control. However, the estimate of the proportion of variance on intention accounted for by the regression is $30,2 \%$. The statistics are: F 5,629 with degrees of freedom $(3,39)$ and the regression is significant $p<0,01$. The Analysis of Variance (ANOVA) was primarily used to see whether similar results were achieved (Table 5).
TABLE 5

Anova

\begin{tabular}{lccccc}
\hline Model & Sum of Squares & df & Mean Square & F & p (F) \\
\hline Regression & 244,332 & 3 & 81,444 & 5,629 & 0,003 \\
Residual & 564,319 & 39 & 14,470 & & \\
Total & 808,651 & 42 & & & \\
\hline
\end{tabular}

In Table 5 the p-value (Sig.) for the F ratio of 5,629 is given as 0,003 , yielding significance. Thus, the F statistic is:

$\mathrm{F}(3,39)=5,629 ; \mathrm{p}<0,01$

Further more, in order to find the contribution of each independent variable of attitude, subjective norm and perceived behavioural control, the beta weights (standardised regression weights) were used (Kerlinger \& Lee, 2000).

TABLE 6

COMPONENTS OF THE MODEL

\begin{tabular}{lccc}
\hline Predictors & á & â & Zero order correlations \\
\hline Attitude & 0,84 & 0,13 & $0,35^{*}$ \\
Subjective norm(SN & 0,69 & 0,49 & $0,53^{* *}$ \\
$\begin{array}{l}\text { Control beliefs } \\
\text { (PBC) }\end{array}$ & 0,73 & $-0,095$ & 0,01 \\
Attitude and SN & & & $0,45^{* *}$ \\
\hline
\end{tabular}

Dependent variable: intention

${ }^{*} \mathrm{p}<0,05$ (one-tailed)

** $\mathrm{P}<0,01$ (one-tailed)

In Table 6 the standardised beta coefficients $(\hat{a}=$ attitude and intention $=0,13$; $(\hat{\mathrm{a}}=$ subjective norm and intention $=0,49)$; and $(\hat{\mathrm{a}}=$ perceived behavioural control and intention $=-0,095)$. Only subjective norm is a significant predictor $p<0,01$ of intention and therefore could contribute to $30,2 \%$ of the variance on intention (R Squared $=0,302$ ).

Overall the findings are contained below in figure 1.

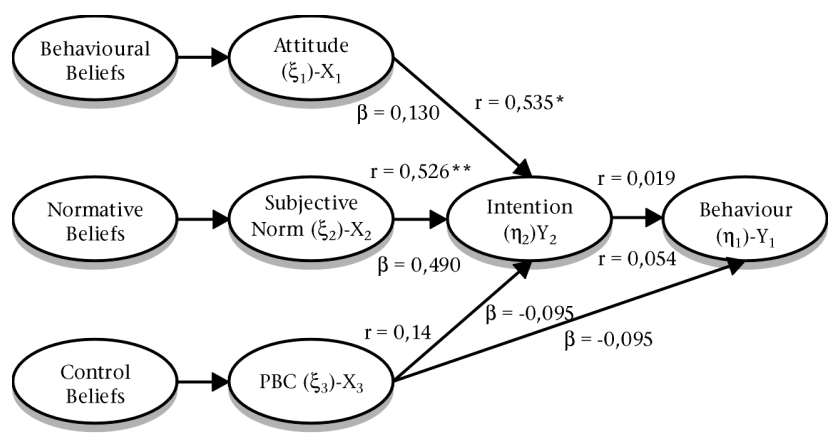

** $(\mathrm{p}<0,01)$ significant at 0,01 level (1-tailed) $*(p<0,05)$ significant at 0,05 level (1-tailed)

\section{Figure 1: TPB model data}

The results showed that subjective norm showed the highest correlation with intention $\mathrm{r}=0,53(\mathrm{p}<0,01)$ (Table 6). The standardised coefficients of the independent variables and intention is: $(\hat{\mathrm{a}}=$ attitude and intention $=0,130$; $(\hat{\mathrm{a}}=$ subjective norm and intention $=0,490)$; and $(\hat{a}=$ perceived behavioural control and intention $=-0,095$ ).

The results of this study indicate that the intention to implement an HIV/AIDS policy and programme by SMEs is 
influenced mainly by subjective norm factors, with attitudinal factors and perceived behavioural control playing a lesser role. These factors explain the proportion of the variability of the intention scores, confirming to some extent the predictive usefulness of the Theory of Planned Behaviour. The data obtained therefore support to some extent the validity of the theory of planned behaviour in assessing behavioural intentions in owner-managers in implementing an HIV/AIDS policy and programme. Finally, subjective norm in implementing an HIV/AIDS policy and programme shows a reasonably strong relationship with intention.

\section{Overall findings}

The present study of the TPB variables (Figure 1) focused on the behavioural intention of SMEs to implement an HIV/AIDS policy and programme. An interesting finding (Table 4) showed subjective norm to contribute strongly as a predictor of intention. The research, however, focused on past behaviour as a self reported measurement in implementing an HIV/AIDS policy and programme. The intention-behaviour correlation (Figure 1) was $(r=0,019)$, indicating that there is no relationship on past behaviour in implementing an HIV/AIDS policy and programme. The research shows that $81 \%$ (Table 2) of the owner managers rated that they strongly disagree with having implemented an HIV/AIDS policy and programme in the last six months. The high percentage $(81 \%)$ of SMEs that have not implemented an HIV/AIDS policy and programme in the last six months and the insignificant relationship of intention and behaviour $(\mathrm{r}=0,019)$, may indicate that SMEs experience difficulty in dealing with HIV/AIDS in the workplace. However, female owner-managers are more likely to deal with HIV/AIDS, as $49 \%$ of males (Table 2) indicated that they "strongly disagreed" with implementing an HIV/AIDS policy/programme in the last six months, whereas $33 \%$ of females (Table 2) indicated that they "strongly disagreed" with implementing an HIV/AIDS policy and programme in the last six months. The implication is that females as owner-managers will most likely respond favourably to implementing an HIV/AIDS policy and programme in the workplace.

Limited support for the efficacy of the TPB over the TRA is provided by the multiple correlations of attitude, subjective norm and $\mathrm{PBC}$ with intention as shown in Table 4. The findings of the present research in Table 4 show that $(\mathrm{R}=$ $0,550, R 2=0,302$ ) provide some evidence of the significance of the TPB and especially subjective norm in its current application. Armitage and Conner's (1999b) study of 185 independent empirical studies showed that the average multiple correlation of attitude, subjective norm and PBC with intention is $\mathrm{R}=0,63$, accounting for $39 \%$ of the variance $\left(\mathrm{R}^{2}=0,43\right)$. Godin and Kok (1996) reported that TPB accounted for $41 \%$ of the variance in behavioural intentions $(\mathrm{R}=0,64 ; 76$ correlations $)$ and $34 \%$ of the variance in behaviours ( $\mathrm{R}=0,58$; 35 correlations) for a range of health behaviours. The present study found $R=0,550(R 2=0,302)$ for the multiple correlation of attitude, subjective norm and PBC with intention (Table 4) and therefore the TPB accounts for $30,2 \%$ of the variance in behavioural intention in implementing an HIV/AIDS policy and programme. However, only attitude and subjective norm was found to be significant (Table 6).

\section{Self -report vs. objective behaviour}

It has been found that many TPB studies do not employ prospective designs or measure behaviour. The present research only focused on self-reported behaviour in implementing an HIV/AIDS policy and programme. Sutton (1998) has further suggested that showing respondents the measure of behaviour on which they will later be assessed could be a way of dealing with subjective and objective measures. Armitage and Conner (1999a) showed that TPB accounts for large, highly significant proportions of variance in prospective measures of both observed $(\mathrm{R} 2=0,20)$ and self reported $(\mathrm{R} 2=0,31)$ behaviour. The implication is in the present study which found $(\mathrm{R} 2=0,302)$ to have limited significance. This shows the limited efficacy of the TPB model in assessing self reported behaviour by SMEs in implementing an HIV/AIDS policy and programme within the past six months. However, researchers should be cognisant of self-reported data and, wherever possible take accurate multiple measures of actual behaviour and increase the measures of control beliefs (PBC) in future applications.

\section{Attitude and Intention}

The attitude towards the behaviour is determined by the relative strength of these associations and by the beliefs that are salient at the time. This works on the principle of Fishbein and Ajzen's (1975) Expectancy-value Model: the subjective value of a given outcome affects the attitude in direct proportion to the strength of the belief. In the TPB model (figure 1) attitude is described as the individual's positive or negative evaluation of performing a particular behaviour, which in this case implementing a HIV/AIDS policy and programme in the workplace (Ajzen, 1988, 1991). The alpha of attitude-beliefs measured $(a=0,84)$ as shown in Table 6 , is acceptable. The findings on the zero order correlation between attitude and intention $(\mathrm{r}=0,353)$ was significant at $\mathrm{p}<0,05$ (1-tailed) (Table 6) and shows that attitude is related to intention to implement an HIV/AIDS policy and programme in the SME workplace, however attitude was found to be not a significant predictor of intention to implement an HIV/AIDS policy and programme (Table 6). The implication is that owner-managers may not have a positive evaluation of implementing an HIV/AIDS policy and programme, and this could reduce the ability of the SME in implementing an HIV/AIDS policy and programme in the workplace.

\section{Subjective Norm and Intention}

In the TPB model, subjective norm is considered to be a function of salient normative beliefs. While subjective norm relates to perceptions of general social pressure to implement an HIV/AIDS policy and programme, the underlying normative beliefs are concerned with the likelihood that specific individuals or SME groups with whom the individual is motivated to comply will either approve or disapprove of the behaviour. As previously indicated, a global measure of subjective norm was obtained with $(\mathrm{a}=0,69)$ as shown in Table 6 , with multiple measures of subjective norm. The findings show a strong zero order correlation between subjective norm and intention $(\mathrm{r}=0,53)$ and the standardised $\hat{\mathrm{a}}=0,49$ was significant at $\mathrm{p}<0,01$ (see Table 6). Furthermore, the findings show that subjective norm is the strongest predictor of behavioural intention in implementing an HIV/AIDS policy and programme in the workplace, contrary to the view of some researchers (Armitage \& Conner, 1999b). The implication is that if business leaders show commitment towards the HIV/AIDS policy and programme, employees could feel the social organisational pressure to effect the behavioural changes required in implementing the HIV/AIDS policy and programme. This implies that business leaders of SMEs should sit on committees, allocate budgets and make important decisions about the implementation of the HIV/AIDS policy and programme (Smetherham, 2003).

Armitage and Conner (1999a) further concluded that the component of subjective norm points to measurement as its principle weakness, given that the majority of TPB studies have used single-item measures. An interesting finding in Table 6 shows a strong zero order correlation between attitude and subjective norm $(r=0,45)$ with significance at 0,01 level (1tailed). Although attitude should not be seen as a causal factor influencing subjective norm, cognisance should still be taken of its positive relationship on subjective norm. Ajzen (1991) has shown that subjective norm can be operationalised as a global perception of social pressure either to comply or not to comply with the wishes of others. Therefore, the formation of 
perceptions about important others in implementing an HIV/AIDS policy and programme is therefore related to the individuals positive or negative evaluation of implementing an HIV/AIDS policy and programme. This finding could prove useful in the design of interventions which take into consideration the influence of social organisational pressure in the implementation of an HIV/AIDS policy and programme within the SME workplace (Ajzen, 1991).

\section{Perceived Behavioural Control (PBC) and Intention}

According to Ajzen (1991) control beliefs are the antecedents of $\mathrm{PBC}$ and are concerned with perceived power of specific factors to facilitate or inhibit performance of the behaviour. Like the other beliefs, the equation takes into account the relevance of the belief to the individual, in this case by taking a measure of the frequency of occurrence of the promoting or inhibitory factors. Control beliefs are those salient beliefs about the factors that may constrain or enhance the behaviour of interest by influencing the perception of an individual regarding the difficulty of performing the behaviour of interest (Ajzen, 1988, 1991). Ajzen further distinguishes between internal factors, such as information; skills and abilities; emotions and compulsions; and external factors, such as opportunity and dependence on others. Respondents were asked to rate the frequency of occurrence and then this was multiplied by the likelihood of relevant control factors. A composite summation was computed and this then provides a belief-based measure of perceived behavioural control (PBC) (Ajzen, 1988; Manstead \& Parker, 1995; Sparks, Guthrie \& Shepard, 1997). The findings in Table 4 and 6 show $(\mathrm{r}=0,14)$ and regression coefficient (standardised $\hat{a}=-0,095$ ) for the correlation between PBC and intention. The weak correlation is supported by findings by Armitage and Conner (1999a). The present study thus shows that a weak intention-behaviour interaction yields a weak PBC-behaviour interaction. PBC shows no relationship to intention and does not significantly explain variance in intention. Ajzen however, distinguishes between internal factors such as information, skills and abilities, emotions and compulsions and external factors such as opportunity and dependence on others that may be relevant.

\section{CONCLUSION}

The progression of the HIV/AIDS epidemic makes it imperative to put measures in place at all levels to minimise its impact. The 2003 UNAIDS report estimates that more than 5 million South Africans were HIV infected at the end of 2003. Further more, about one quarter of South Africans' from the economically active population could be infected. Given these statistics, it is clear that HIV/AIDS is poised to have a significant effect on every facet of the population, and small and medium (SME) enterprises are not immune. Present research indicates that small businesses are more at risk as they are less able to absorb the effects of the HIV/AIDS epidemic.

The impact on businesses could be felt through reduced productivity, increased absenteeism, increased staff turnover, increased recruitment and training costs, increased cost of employee benefits and poor staff morale. The overall research objective was to assess the behavioural intentions of SMEs in the implementation of an HIV/AIDS policy and programme. The results are reflected below:

- Attitude has a positive relationship on intention, but does not significantly explain variance in intention. Intention is linearly dependent on attitude.

- Subjective norm has a positive relationship on intention and significantly explains variance in intention. Attitude also is positively related to subjective norm. Intention is linearly dependent on subjective norm.

- Perceived behavioural control has no relationship on intention and does not significantly explain variance in intention.
Although, the overall regression equation was significant $F$ $(3,39)=5,629 ; p<0,01$ with $(\mathrm{R} 2=0,302)$ in which $30,2 \%$ of the variance in intention is explained by the predictors attitude, subjective norm and perceived behavioural control, further analysis of the regression coefficients of the sample indicate that only subjective norm $(\hat{a}=0,508)$ significantly explains variance in intention to implement an HIV/AIDS policy and programme, contrary to the findings of Quine, Rutter and Arnold (1998).

- Researchers should be aware of the problems of self report data with respect to bias (Gaes, Kalle \& Tedeschi, 1978) and wherever possible take an accurate multiple measure of actual behaviour in implementing an HIV/AIDS policy and programme. If a linear relationship exists between attitude and subjective norm with behavioural intention to implement an HIV/AIDS policy and programme, then it will imply that SME's (owner-managers) need to understand attitudes and its influence in shaping perceptions about what other SME's are doing successfully to implement an HIV/AIDS policy and programme in the workplace. The writer is of the opinion that this can relate to governments, organisations, HIV/AIDS activists and other role players. SME's should focus on positive attitudes towards other SME's and or significant others, which could influence the positive perceptions of implementing an HIV/AIDS policy/programme. Ultimately, this could lead to the formation of a behavioural intention to implement an HIV/AIDS policy and programme.

The long term sustainable business responses will only be achieved if all stakeholders within companies (leaders, managers, personnel and shareholders), are convinced of the real business rationale for action i.e. implementing an HIV/AIDS policy and programme in the workplace. In particular, committed and knowledgeable leadership is needed to ensure that the policy and programme gets implemented. In order to ensure optimal success of its HIV/AIDS initiatives, SMEs should take cognisance of the needs, attitudes and demands of all its employees, suppliers and clients (Whiteside \& Sunter, 2000). The present study showed that subjective norm is the strongest predictor of intention to implement an HIV/AIDS policy and programme.

The formation of perceptions about important others such as the business manager-owner in implementing an HIV/AIDS policy and programme is related to the employees' positive or negative evaluation of implementing an HIV/AIDS policy and programme. This finding could prove useful in the design of interventions, which should take into consideration the influence of social organisational pressure exerted by the ownermangers in the implementation of HIV/AIDS policy and programme within the SME workplace (Ajzen, 1991). A clear understanding of specific impacts of HIV/AIDS on SMEs and the context in which these occur, is a critical factor in the development of an effective and appropriate HIV/AIDS policy and programme. The implementation of an HIV/AIDS policy and programme will be a significant step towards reducing the impact on various organisations and companies. Thus, the importance of identifying the impact and implementing an HIV/AIDS policy and programme on individual SMEs cannot be further emphasised.

\section{Limitations}

There are some limitations to the study that must be acknowledged. The first of these relate to the nature of the sample. Although the sample chosen did produce findings that showed the limited usefulness of the application of TPB in assessing behavioural intention of SME's in implementing an HIV/AIDS policy and programme, caution must however, be exercised in its generalisability. Nonetheless, since many owner-managers of the population are confronted with HIV/AIDS and the need to implement an HIV/AIDS policy and programme, the study may prove insightful into the considerations that affect the behavioural intention to implement an HIV/AIDS policy and programme. 
Secondly, the study used a global measure of subjective norm. Although it may be in violation of Ajzen and Fishbein's earlier conceptualisation, the study showed that a global measure using multiple scale items is useful for TPB studies. Future research should consider an increase in the number of outcome belief items as generated in the present study.

\section{Recommendations for future research}

Two possible avenues for future research can be identified. Firstly, an investigation of salient beliefs underlying perceived behavioural control and self efficacy across various SME sectors toward implementation of HIV/AIDS policy and programme in the SME workplace could prove useful; and secondly, a study could be conducted to test whether self efficacy and $\mathrm{PBC}$ correlate with intention and behaviour significantly more strongly than perceived control over behaviour in implementing an HIV/AIDS policy and programme.

\section{REFERENCES}

Ajzen, I. (1988). Attitudes, personality and behaviour. Milton Keynes: Open University Press.

Ajzen, I. (1991). The theory of Planned behaviour. Organisational Behaviour and Human Decision Process, 50, 179-211.

Ajzen, I. (1998). Models of human social behaviour and their application. Psychology and Health, 13, 735-740.

Ajzen, I. \& Fishbein, M. (1980). Understanding Attitudes and Predicting Social Behaviour. New York: Prentice-Hall.

Ajzen, I. \& Madden, T.J. (1986). Prediction of goal directed behaviour: Attitudes, intentions, and perceived behavioural control. Journal of Experimental Social Psychology, 22, 453-474.

Armitage, C.J., \& Conner, M. (1999a). The theory of planned behaviour: Assessment of predictive validity and perceived control. British Journal of Social Psychology, 38, 35-54.

Armitage, C.J. \& Conner, M. (1999b). Predictive Validity of the theory of planned behaviour: The role of questionnaire format and social desirability. Journal of Community and Applied Social Psychology, Jul-Aug, 9 (4), 261-272.

Cassell, C., Nadin, S., Gray, M. \& Clegg, C. (2002). Exploring Human Resource management practices in small and medium sized enterprises. Personnel Review, 31 (6), 671-692.

Christianson, D (2001). Leadership. New Africa Publication Ltd, pp. 42-44.

Coates, T.J. \& Feldman, M.D. (1997). An overview of HIV prevention. Journal of Acquired Immune Deficiency Syndromes and Human Retrovirology, 14, 13-16.

Conner, M. \& Norman, P. (1994). Comparing the health belief model and the theory of planned behaviour in health screening. In D.R. Rutter and L. Quine (Eds), Social psychology and health: European perspectives (pp.1-24), UK: Avebury

Fishbein, M. \& Ajzen, I. (1975). Belief, attitude, intention and behaviour: An introduction to theory and research. London: Addison-Wesley.

Gaes, G.G., Kalle, R.J. \& Tedeschi, J.I. (1978). Impression management in the forced compliance situation: Two studies using the bogus pipeline. Journal of Experimental Social Psychology, 9, 491-501.

Godin, G. and Kok, G. (1996). The theory of planned behaviour: A review of its applications to health-related behaviours, American Journal of Health promotion, 11, 87-98.
Goss, D. \& Adam-Smith, D. (1995). Organising Aids: Workplace and Organisational Responses to the HIV/AIDS Epidemic. London: Taylor \& Francis Ltd.

Hardeman, W., Johnston, M., Johnston, D.W., Bonneti, D., Wareham,N., \& Kinmonth, A. (2002). Application of the theory of planned behaviour change interventions: A systematic review. Psychology and Health, Apr, 17 (2), 123-158.

Hendry, C., Arthur, M.B. \& Jones, A.M. (1995). Strategy through people: Adaptation and learning in small and medium enterprises. London: Routledge.

Jonas, K. \& Doll, J. (1996). A critical evaluation of the theory of reasoned action and the theory of planned behaviour. Journal for Social Psychology, 27, 18-31.

Keil, J.M. \& Schellenberg, E.G. (1998). Compensating people with AIDS: A different perspective. Canadian Journal of Behavioural Science, 30, 82-90.

Kerlinger, F.N \& Lee,H.B. (2000). Foundations of Behavioral Research. New York: Harcourt College Publishers.

Kinnear, P.R. \& Gray, C.D. (2000). SPSS for Windows Made Simple. Hove: Psychology Press.

Kirby, D. (1995). A Review of educational programs designed to reduce sexual risk taking behaviours among school aged youth in the US, California: ETR Association.

Manstead, A.S.R. \& Parker, D. (1995). Evaluating and extending the theory of planned behaviour. In W. Strobe \& M. Hewstone (eds), European Review of Social Psychology (vol. 6, pp 69-95). Chichester: Wiley.

Olson, J.M. \& Zanna, M.P. (1993). Attitudes and Attitude Change. Annual Review of Psychology, 44, 117-154.

Quine, L., Rutter, D.R. \& Arnold, L. (1998). Predicting and understanding safety helmet use among schoolboy cyclists; A comparison of the theory of planned behaviour and the health belief model, Psychology and Health, 13, 251-269.

Shaughnessy, J.J. \& Zechmeister, E.B. (1997). Research methods in psychology (4th ed.) New York: McGraw-Hill.

Smetherham, J.A. (2003). Business leaders not doing enough about HIV/Aids-report. Cape Times, p.5.

South Africa (1995). National Strategy for the Development and promotion of Small Business in South Africa. Department of Trade and Industry, Cape Town.

Sparks, P., Guthrie, C.A., Shepard, R. (1997). The dimensional structure of perceived behavioural control construct. Journal of applied social psychology, 27 (5), 418-438.

Stanton, B., Kim, N., Galbraith, J and Parrot, M. (1996). Design issues addressed in published evaluations of adolescent HIVrisk reduction interventions: a review. Journal of Adolescent Health, 18, 387-396.

Sutton, S. (1998). Explaining and predicting intentions and behaviour: How well they are doing? Journal of Applied Social Psychology, 28, 1318-1339.

UNAIDS, World Health Organisation (2002 update). Epidemiological Fact Sheets on HIV/AIDS and Sexually Transmitted Infections.

UNAIDS, World Health Organisation (2003 update). Epidemiological Fact Sheets on HIV/AIDS and Sexually Transmitted Infections.

Wager, G.J., Remien, R.H. \& Carballo-Dieguez, A. (1998). Extramarital sex: is there an increased risk for HIV transmission? A study of male couples of mixed HIV status. Aids Education and Prevention, 10, 245-256.

Whiteside, A. \& Sunter, C. (2000). AIDS, The challenge for South Africa. Cape Town: Human \& Rousseau. 